\title{
Influence of Different Surface Texture Parameters on the Contact Performance of Piston Ring-Sleeve Friction Pair of Hydraulic Cylinders
}

\author{
Wen'an Wang, ${ }^{1}$ Zhiqi Liu $\mathbb{D}^{1}{ }^{1}$ Dongliang Chen, ${ }^{1}$ Zhiming Xie, ${ }^{1}$ and Jianli Song ${ }^{2}$ \\ ${ }^{1}$ School of Mechanical Engineering, Taiyuan University of Science and Technology, Taiyuan 030024, China \\ ${ }^{2}$ School of Instrumentation Science and Optoelectronics Engineering, Beijing Information Science and Technology University, \\ Beijing 100192, China \\ Correspondence should be addressed to Zhiqi Liu; liuzhiqi@tyust.edu.cn
}

Received 28 May 2021; Revised 20 July 2021; Accepted 2 August 2021; Published 16 August 2021

Academic Editor: Francesco Ruffino

Copyright (C) 2021 Wen'an Wang et al. This is an open access article distributed under the Creative Commons Attribution License, which permits unrestricted use, distribution, and reproduction in any medium, provided the original work is properly cited.

\begin{abstract}
The surface texture, a major way to decrease friction and wear of the cylinder-piston ring friction pair, was conducted on cylinderpiston ring friction pair specimen using the orthogonal experimental design method to investigate the effect of different texture parameters (size, depth, shape, and surface density) of the friction and wear characteristics. Through simulation analysis, the texture parameters that affect the friction and wear characteristics are obtained. Using the evaluation method of friction coefficient and mass wear rate, the influence sequence and optimal values of texture parameters that affect friction and wear characteristics are obtained through range analysis. The results show that, after surface texture treatment under mixed lubrication conditions, the friction characteristics of the friction pair have changed and the friction coefficient and friction and wear rate have been significantly reduced. The results show that the triangular texture has a good antifriction effect, the texture depth is deepened, and the surface density and the size increases have a positive effect on the improvement of friction and wear. An ultra-depth microscope was used to observe the wear morphology of the friction and wear tests. The results show that the weakening of the third body wear by the texturing treatment and the maintenance of oil lubrication are the main reasons for reducing friction and wear.
\end{abstract}

\section{Introduction}

Hydraulic cylinder is a common hydraulic actuator that converts hydraulic energy into mechanical energy. It has the advantage of simple structure, and high reliability can realize linear reciprocating motion (or swing motion). It can be used solely or combined with other components, so it is widely used in hydraulic systems [1]. Piston ring-sleeve friction pair has been under heavy load and high load for a long time; its friction performance and service life are important factors that affect the overall service life and reliability of the cylinder [2]. In the current research, although the material improvement of the hydraulic cylinder-piston ring has achieved initial results, some treatment methods are still needed to further improve the performance and extend its service life.
Texturing is a method of texturing smooth surfaces to improve surface contact performance [3-5]. The main method is to introduce well-defined identical features (such as discrete pits and grooves) on the contact surface [6]. The texture can be used as a lubricant reservoir to provide lubricant to the contact surface in the case of insufficient lubrication and to capture wear debris to minimize third body wear [7-10]. Texturing is widely used in cutting tools, internal combustion engine pistons, mechanical seals, and bearings [11-17]. Current research and applications show that texturing processing is feasible and effective, has a wide range of application scenarios, and has a good application prospect in future industrial production.

Current research shows that texture parameters mainly involve four parameters of texture size, depth, shape, and surface density. Qiu and Khonsari [18] mainly studied the 
influence of the size of the texture on the bearing capacity. The texture improves the bearing capacity of the oil film through cavitation. Etsion et al. [19] studied the influence of different texture depths on oil film bearing capacity and antifriction performance. Wang et al.'s [20, 21] research shows that when the texture depth is close to the oil film thickness, the oil film bearing capacity reaches its peak; when it is slightly larger than the oil film thickness, the abrasion resistance and surface integrity are the best; when it is less than the oil film thickness, the texture becomes negative effect. The research of Guzek et al. [22-24] compared the effects of rectangular, elliptical, spherical, and other texture shapes on the bearing capacity and the antifriction properties of the oil film. Studies [25] have shown that rectangular texture has obvious advantages in bearing capacity, spherical texture has significant effects on contact performance and friction reduction, and the texture effect is best when the contact surface slides along the long axis of the elliptical texture. Xiao et al. [26, 27] found that tilting or stepping the bottom of the texture can effectively increase the thickness of the oil film. Zhang et al. $[28,29]$ conducted a series of studies on the influence of the surface density of the texture. The studies found that the lowest density at which the texture produces a positive effect is about $8.6 \%$; the texture density of oil-lubricated metal components is between $5 \%$ and $13 \%$ and, at this time, the antifriction rate is the highest; and the texture density should be avoided as much as possible to exceed $25 \%$ to avoid stress concentration. Henry et al.'s [30] research shows that higher texture density is more beneficial. In their experiments, it was shown that texture with $30 \%$ areal density has better results and the stress concentration is not obvious. However, the test results also show that the fully textured contact indicates low efficiency, so there is still an upper limit on the surface density of the texture. The influence of texture parameters on the bearing capacity and antifriction properties of the contact surface is more than that of the above-mentioned factors. For example, Guzek et al. [22, 31] also found that the texture distribution on the fixed surface is more efficient because the texture on the moving surface will cause pressure accumulation at the lubricating fluid inlet due to the squeezing effect. Of course, texturing on the two contact surfaces will produce additional effects. In the current research, the main consideration for the application of texture is the influence of related parameters, and different texture parameters are designed for different application scenarios. For example, in $\mathrm{Xu}$ et al.'s [32-36] research, the application of different texture parameters in cylinders was studied, and friction and wear tests were carried out on the textured elements using a friction and wear machine. The research results provided a good understanding for the lubrication mechanisms of different textured surfaces.

However, the current research on texture processing technology is still relatively limited. On the one hand, it fails to effectively combine multiple parameters. On the other hand, there is no reference for the texture processing parameter settings, and the parameter data has no simulation or theoretical basis. This paper uses simulation methods to determine the texture processing parameters and uses the orthogonal test method to study the order and optimal value of the texture processing methods of different sizes, depths, shapes, and surface densities on the hydraulic cylinderpiston ring friction pair. The wear morphology of the friction contact surface after texture treatment was analyzed by SEM electron microscope.

\section{Texture Parameter and Methods}

2.1. Texture Parameter Setting. The current research mainly focuses on two aspects of the friction reduction effect of the contact surface and the improvement of the bearing capacity by the change of texture parameters. However, in the current experimental research, most of the texture parameters are determined without theoretical guidance; there is no experimental verification for the theoretical research on texture parameters. In this paper, a simulation study of texture parameters is carried out, and the texture parameters are determined by the CFD method and MATLAB simulation technology, combined with relevant research conclusions and analysis, which is used as the basis for subsequent orthogonal experiment parameter settings.

The setting of texture parameters mainly involves four aspects of texture size, depth, shape, and areal density. The texture parameters directly determine the thickness and bearing capacity of the oil film, so the parameter settings in this article are based on the oil film and bearing capacity as a setting reference. The depth of the texture is a parameter that directly affects the thickness of the oil film. The relationship between the thickness of the oil film and the depth of the texture is shown in the following formula and Figure 1:

$$
h=h_{0}+h_{p}
$$

2.2. Texture-Influencing Factors. The main parameters that affect the texture are the size, depth, shape, and surface density of the texture. According to the research of Sahlin et al. [37], when the depth of the texture is close to the depth of the internal circulation (vortex) generated by the fluid in the texture, the texture has the greatest bearing capacity. In the study of Cupillard et al. [38-40], this depth is defined as the critical depth of the texture. In the study of Du et al. $[21,41]$, it is shown that the roughness has a certain influence on the average depth of the texture of the contact surface. When the roughness is close to the depth of the texture, the rough surface will adversely affect the texture. In addition to depth, the shape of the texture also affects the thickness and bearing capacity of the oil film lubricated. Fouflias et al. [42] conducted a study on the influence of textures of different shapes on the thickness of the oil film and showed that the appropriate texture shape has a positive effect on the thickness of the film. Papadopoulos et al.'s [43] research found that the rectangular texture has the greatest bearing capacity in oil film lubrication. The study of $\mathrm{Hu}$ et al. [44] shows that different texture shapes have a certain effect on the stability of the lubricating oil film. In this section, MATLAB and ANSYS simulations are performed on the four parameters that affect the texture performance, namely, 


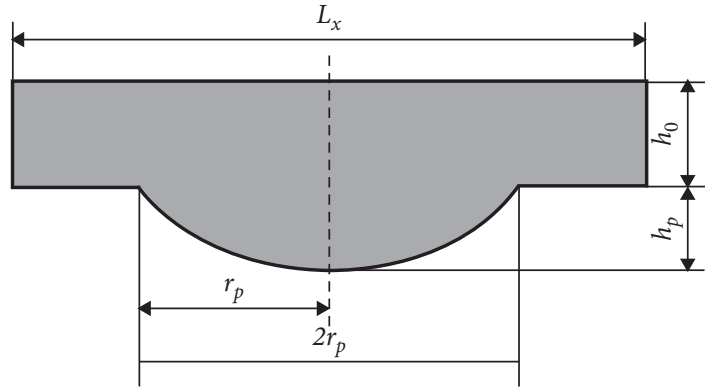

FIGURE 1: Relationship between oil film thickness and texture depth.

texture size, depth, shape, and surface density. The simulation results verify the influence of the four parameters on the texture's oil absorption capacity and oil film bearing capacity.

Using MATLAB to simulate the thickness of the oil film formed by the texture of different shapes, the simulation results are as shown in Figures 2-4.

According to the simulation results of Figures $5-8$, it is found that textures of different shapes have different effects on the thickness of the oil film, which is reflected in the difference in the shape and thickness of the oil film gain. The results show that the appropriate texture shape has a certain positive effect on the thickness of the oil film.

Because the size and depth of the texture have a certain impact on the oil absorption capacity of the texture, this paper uses ANSYS software to simulate the size and depth of the texture on the oil absorption capacity of the texture. The flow field simulation uses a steady-state flow field model to simulate the flow state of oil flowing through the texture under actual working conditions. The simulation sets up 1500 iterations and converges when the iteration error is less than one-thousandth.

CFD simulation uses the pressure of the hydraulic cylinder under actual working conditions as the inlet pressure of $32 \mathrm{MPa}$ and the actual pressure setting of the outlet pressure of $31 \mathrm{MPa}$ to calculate the oil flow through the texture area under the steady flow field. The oil is conventional hydraulic oil. The temperature is designed for 40 degrees Celsius under normal working conditions. We analyzed the depth and size of different textures on the flow of oil through the texture area. The analysis results show that the size, depth, and surface density of the texture have a certain effect on the ability of the texture to absorb oil. When the ratio of size to depth is appropriate, the ability of the texture to absorb oil increases, corresponding to the increase of oil flow lines inside the texture in the simulation diagram in the streamline diagram. The oil enters the texture and forms an internal circulation within the texture, indicating that the oil is retained inside the texture.

In this section, MATLAB is used to verify the influence of texture shape on the bearing capacity of the oil film, and the CFD method is used to verify the influence of texture size, depth, and areal density on the maintenance of the oil film by the texture preservation oil. The two simulations verify the retention of the texture on the oil film through two different angles. The simulation results

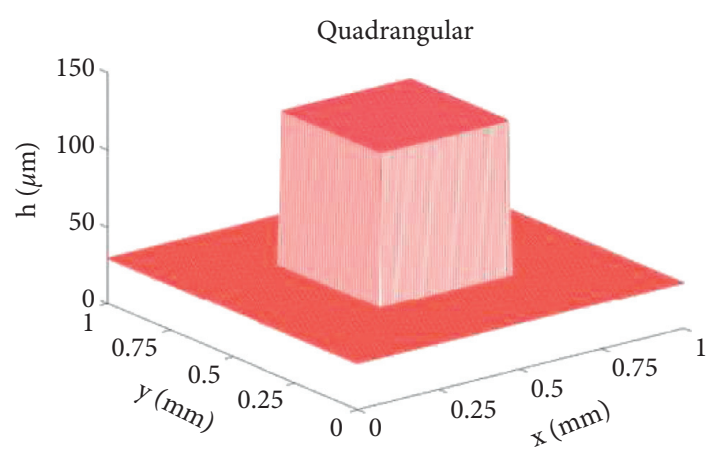

FIgURE 2: Quadrangular texture oil film gain diagram.

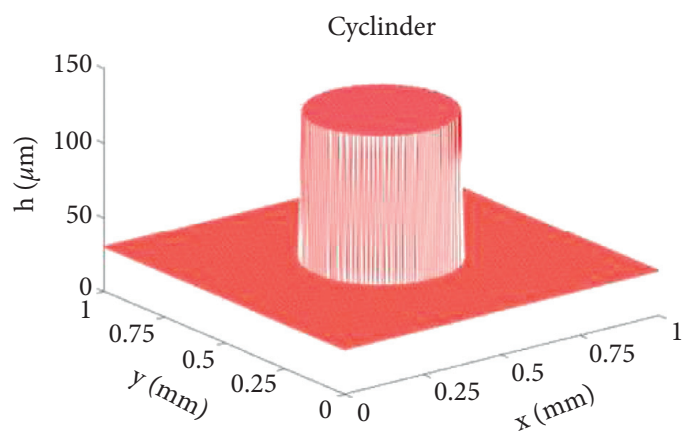

Figure 3: Cylinder texture oil film gain diagram.

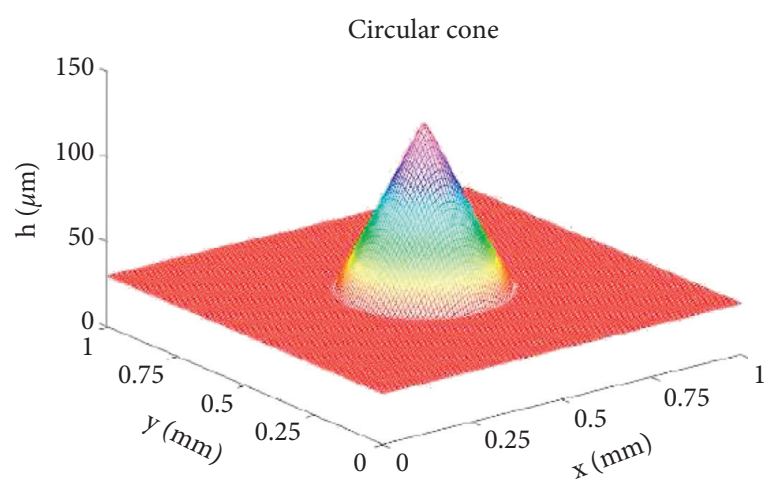

Figure 4: Circular texture oil film gain diagram.

finally determine the comprehensive influencing parameters of texture, namely size, depth, shape, and surface density.

\section{Test Preparation}

The test samples were prepared by using 59\# copper, which is commonly used for piston rings, and 45\# steel, which is commonly used for hydraulic cylinders, as the test materials, and the samples were prepared. A laser beam was used to process the micro-textured array on the surface of the 59\# copper piston ring sample, and the friction-reducing effects of different texture parameters were compared through the friction and wear test in the orthogonal test method. The selection of each factor level is shown in Table 1, because the 

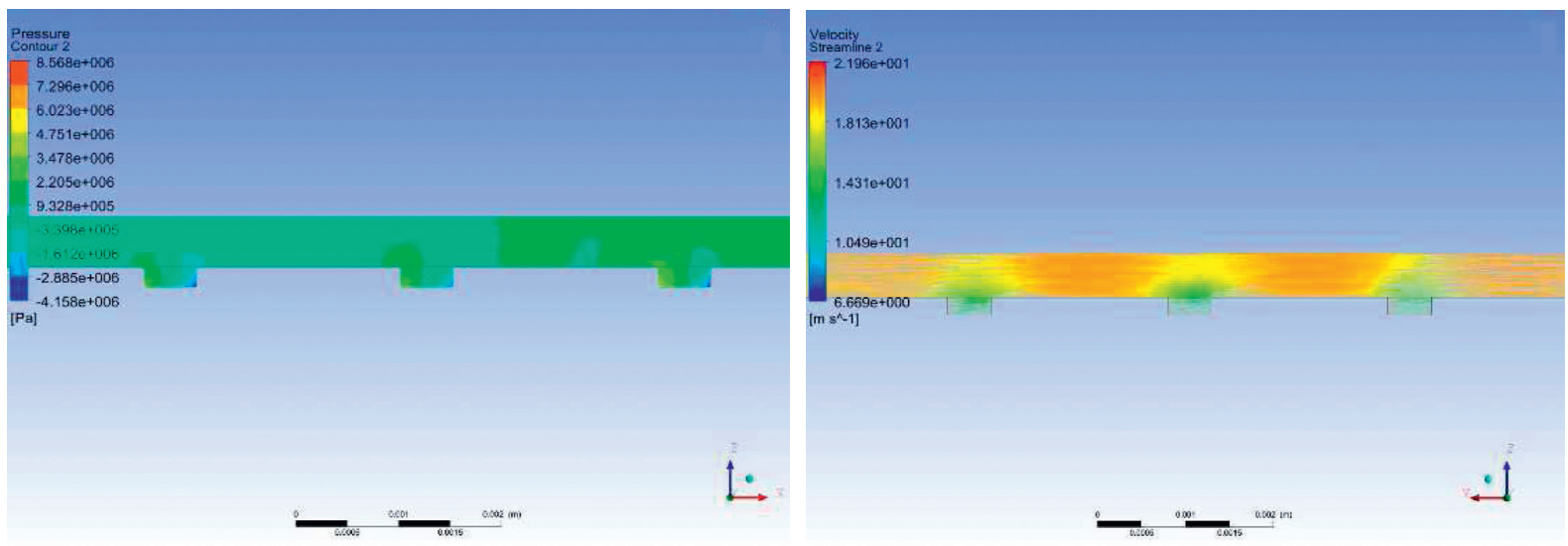

FIGURE 5: 500 micron diameter and 200 micron depth texture fluid pressure diagram and streamline diagram.
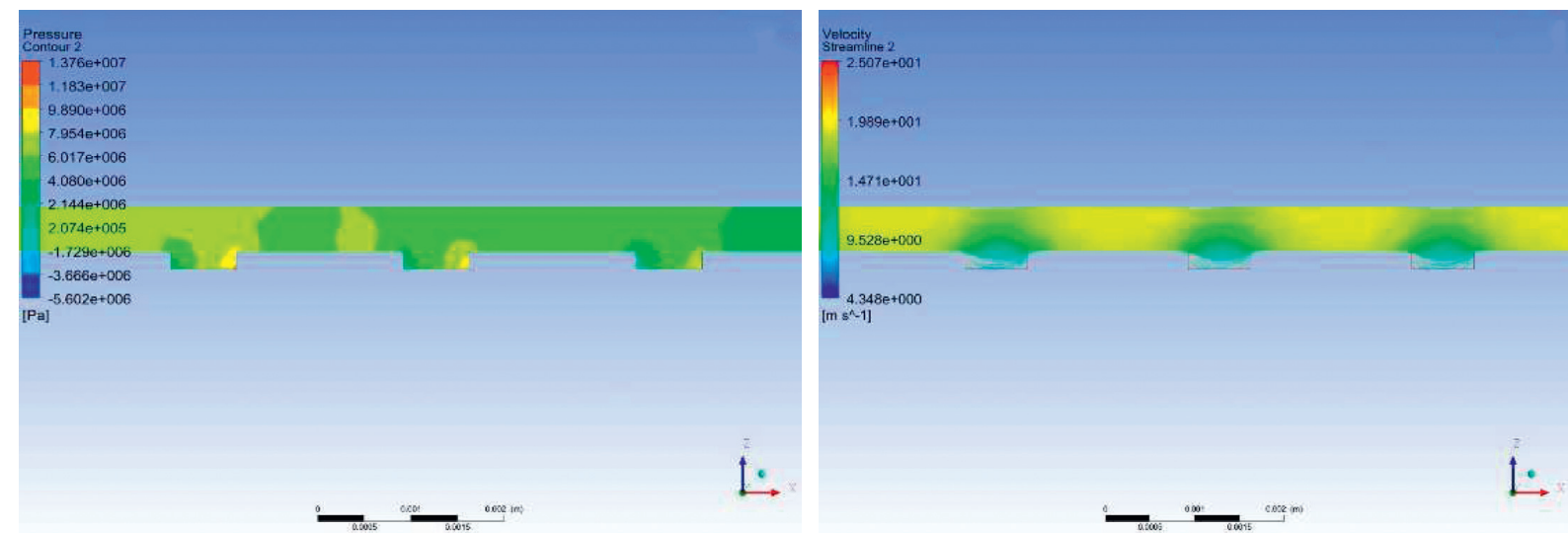

FIGURE 6: 700 micron diameter and 200 micron depth texture fluid pressure diagram and streamline diagram.
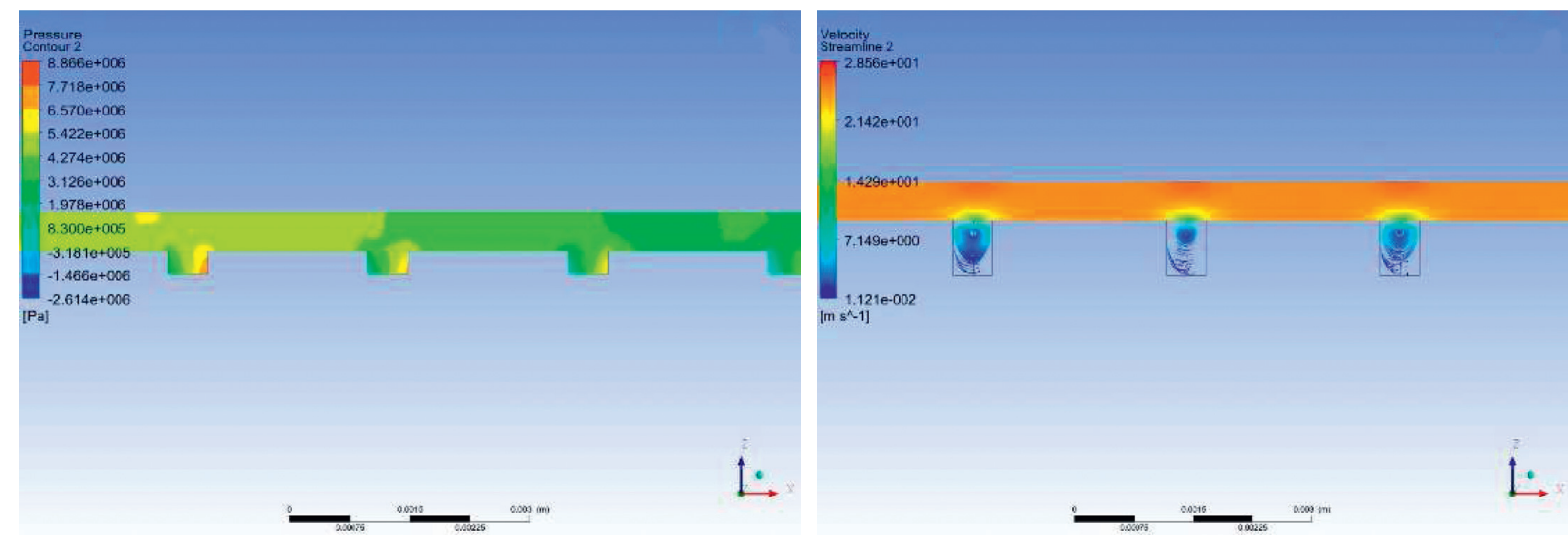

Figure 7: 500 micron diameter and 300 micron depth texture fluid pressure diagram and streamline diagram.

$\mathrm{L}_{16}\left(4^{4}\right)$ orthogonal sequence design experiment is used. The interaction of the main factors was ignored. In addition, a control untextured test group and a parameter median control group were set up to conduct comparative friction tests with and without oil lubrication.

3.1. Material Preparation. The raw materials used in the test are 59\# brass sample and 45\# steel friction block.
According to the test equipment and the purpose of the test, the brass sample is set as a sheet sample with a thickness of $25 \mathrm{~mm}^{*} 25 \mathrm{~mm}$ and a size of $5 \mathrm{~mm}$. The steel friction block is cut according to the size of the fixture. First, the copper sheet is polished to ensure its surface roughness and parallelism. Second, the steel friction block is polished to ensure its parallelism so that the steel block and the copper sheet can achieve surface-to-surface friction. 

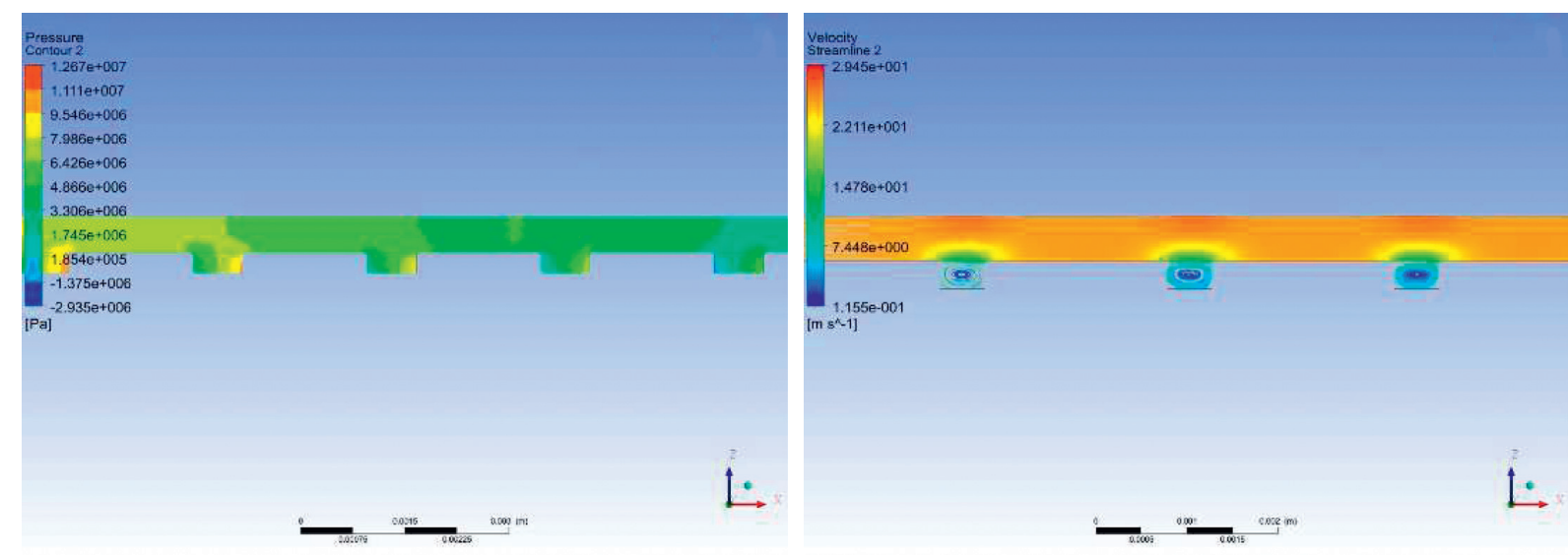

FIGURE 8: 700 micron diameter and 300 micron depth texture fluid pressure diagram and streamline diagram.

TABLE 1: Levels of factors in texture parameters.

\begin{tabular}{lcccc}
\hline & \multicolumn{4}{c}{ Levels } \\
\hline Factors $(j)$ & 1 & 2 & 3 & 4 \\
Texture diameter $(\mu \mathrm{m})$ & 500 & 300 & 700 & 900 \\
Texture shape & Rectangle & Circle & Triangle & Rhombus \\
Texture depth $(\mu \mathrm{m})$ & 100 & 200 & 300 & 400 \\
Surface density $(\%)$ & 2 & 4 & 6 & 8 \\
\hline
\end{tabular}

3.2. Texturing. Laser equipment is used to texture the copper sample. The texture processing includes the following parameters: texture size (diameter), shape, depth, areal density, processing form, and texture surrounding material organization structure. In this study, the texture size, shape, depth, and surface density are the main influencing factors, and the orthogonal design method is used for texture processing. Each level factor is selected as shown in Table 1, so the $\mathrm{L}_{16}\left(4^{4}\right)$ orthogonal design is adopted, and the interaction of the main factors is not considered, as shown in Table 2. Ultrasonic washing is performed on the textured copper sample to wash away impurities and laser burning products. It is ensured that the laser-processed textured surface presents the required four shapes and the texture presents the correct size and depth. The area density design is obtained by dividing the area treated by the texture by the total area. After cleaning, it is necessary to check whether the area density meets the design requirements again. Then, the BSM220 precision balance is used to weigh the sample before the friction test, and the data are recorded.

3.3. Friction and Wear Test. The dry sliding wear test was carried out at room temperature using a multifunctional tribometer (Zhongke Kaihua CFT-I), which was equipped with a block-to-disk assembly, as shown in Figure 9. A normal load of $80 \mathrm{~N}$ was applied to the $45 \#$ steel friction block, it was slid at a speed of $10 \mathrm{~mm}$ in radius and rotated for 120 minutes at a speed of $900 \mathrm{rpm}$. In the test process, the PLC control needle tube oil injection method was used to supplement the oil of the friction pair to simulate the state of mixed friction with exhausted oil in actual working conditions. In addition to the friction test on the 16 specimens in the orthogonal test table, the friction and wear tests on the median level specimens of the four factors and the untextured specimens were carried out. The test conditions were the same as those in the orthogonal test table. After the friction and wear tests were over, the test piece was ultrasonically cleaned again with absolute ethanol. The BSM220.4 high-precision balance was used to weigh the specimen after the wear test, and the data were recorded.

3.4. Wear Observation. After cleaning the copper sheet, pictures were taken with an ultra-depth field again to observe the annular friction area formed by rotating friction. The focus was on the observation of plow-shaped grooves caused by common friction and the wear and scratch morphology caused by friction in the third body wear. The wear width and furrow depth of the corresponding area were measured.

\section{Results and Discussion}

4.1. Hardness Analysis. According to [45], when the laser is used to texture the metal surface, the heating and burning process of the laser may cause the local hardening of the material, which indirectly improves the wear resistance of the material surface. To avoid the influence of the hardening of the material itself on this test, this paper uses a microhardness tester to test the microhardness of the specimens before and after the texturing treatment. The test results show that the texturing treatment has no significant effect on the hardness of the copper sample $(163 \mathrm{HV} \sim 166 \mathrm{HV})$. It can be considered that, in this experiment, the hardening and strengthening effect of laser processing technology on the material can be ignored.

4.2. Friction Analysis. The friction coefficient is a direct manifestation of the pros and cons of the friction performance. The multifunctional tribometer in this test can display the friction coefficient between the contact surfaces in real time. The friction coefficient comparison chart is shown in Figure 10. 
TABLE 2: The $\mathrm{L}_{16}\left(4^{4}\right)$ orthogonal array of texture parameters.

\begin{tabular}{lcccc}
\hline Exp. no. & Texture diameter $(\mu \mathrm{m})$ & Texture shape & Texture depth $(\mu \mathrm{m})$ & Surface density $(\%)$ \\
\hline S1 & 500 & Rectangle & 100 & 2 \\
S2 & 500 & Circle & 200 & 300 \\
S3 & 500 & Triangle & 400 & 6 \\
S4 & 500 & Rhombus & 200 & 6 \\
S5 & 300 & Rectangle & 100 & 8 \\
S6 & 300 & Circle & 400 & 2 \\
S7 & 300 & Triangle & 300 & \\
S8 & 300 & Rhombus & 300 & \\
S9 & 700 & Rectangle & 400 & \\
S10 & 700 & Circle & 100 & \\
S11 & Triangle & 200 & 4 \\
S12 & 700 & Rhombus & 400 & 2 \\
S13 & 700 & Rectangle & 300 & 8 \\
S14 & 900 & Circle & 200 & 6 \\
S15 & 900 & Triangle & 100 & 4 \\
S16 & 900 & Rhombus & \\
\hline
\end{tabular}

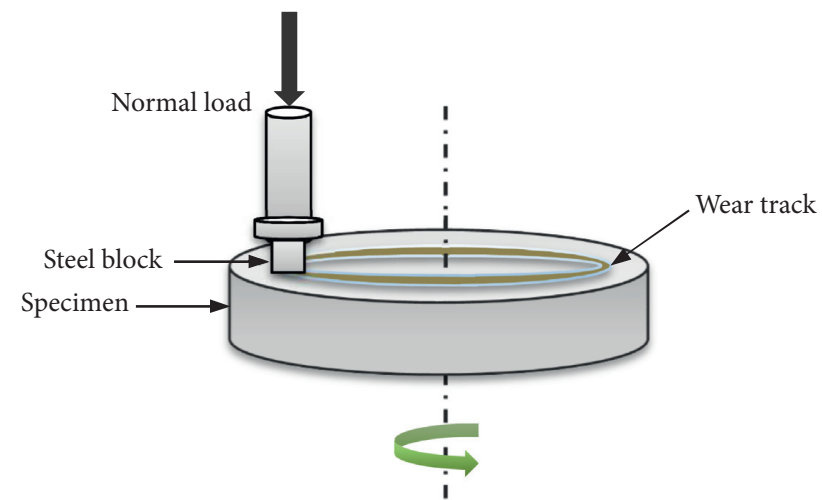

FIGURE 9: Schematic of the block-on-disc wear test.

Figure 10 shows the real-time monitoring graph of the friction coefficient under working conditions, dry friction conditions, and mixed friction conditions. The working condition is the load force obtained by multiplying the contact area by the actual hydraulic oil pressure. In the case of actual load force, considering the commutation speed and working length of the actual hydraulic cylinder, the corresponding rotation speed is $900 \mathrm{rpm}$, and the test is performed with $120 \mathrm{~min}$ as the test time. Analyzing the friction coefficient changes in the graph, it can be found that, compared with the oil-free friction, the friction coefficient between the copper sample and the steel block grinding head decreases significantly under the mixed lubrication condition, indicating that the oil film has a significant antifriction effect. Comparing the friction coefficient curve of the sample after the texture treatment and the friction coefficient curve of the sample without the texture treatment, we can find that the friction coefficient of the sample without the micro-texturing treatment is still significantly greater than that of the sample after the texturing treatment, and the friction coefficient curve of the sample after the texturing treatment is smoother. This shows that the samples after the texturing treatment indicate that the texture has a significant effect on

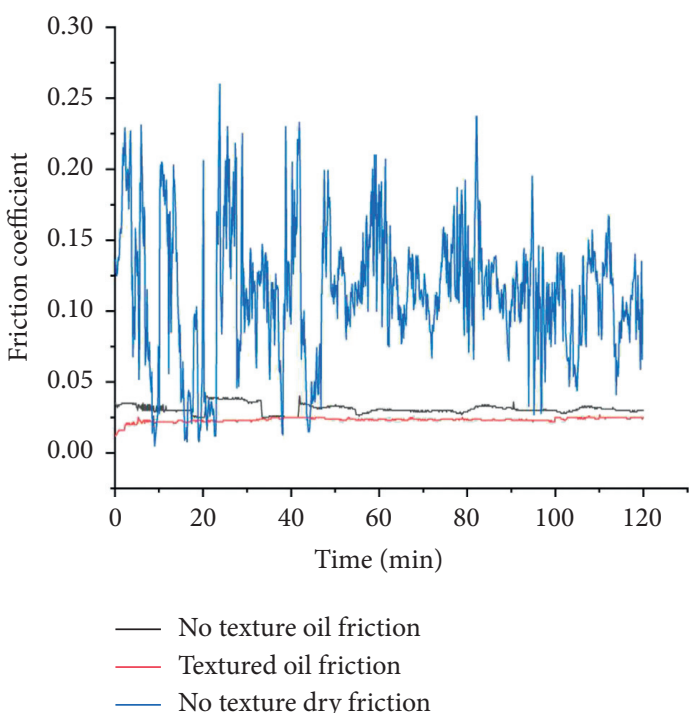

Figure 10: Friction coefficient curves of friction pairs under different conditions.

maintaining the stability of the oil film and ensuring the integrity of the oil film [46].

4.3. Wear Analysis. Table 3 lists the abrasion test results of the 16 texture samples of the orthogonal test group and the untextured smooth samples. Taking the mass loss of the smooth sample as a reference, the relative wear rate of the textured sample is less than 1 , indicating that the textured sample has better wear resistance under mixed friction conditions.

In order to obtain the optimal value of the texture parameter, the friction and wear results of the orthogonal test group were analyzed by range. The results of the range analysis are listed in Table 4.

The results of $C>A>B>D$ show that the texture factors that affect friction and wear are depth, size, shape, and surface density in order. The best results of $A_{3} B_{3} C_{3} D_{4}$ show 
TABLE 3: Wear test results of friction test specimens.

\begin{tabular}{lcc}
\hline Exp. no. & Wear loss $(\mathrm{mg})$ & Relative wear rate (\%) \\
\hline Smooth specimen & 12.3 & 100 \\
S1 & 4.5 & 36.59 \\
S2 & 3.0 & 24.39 \\
S3 & 2.2 & 18.89 \\
S4 & 0.4 & 3.25 \\
S5 & 1.7 & 13.82 \\
S6 & 3.0 & 24.39 \\
S7 & 2.4 & 19.51 \\
S8 & 1.8 & 14.63 \\
S9 & 2.3 & 18.70 \\
S10 & 1.1 & 9.94 \\
S11 & 1.0 & 8.13 \\
S12 & 1.6 & 13.01 \\
S13 & 2.5 & 20.33 \\
S14 & 0.9 & 7.32 \\
S15 & 1.9 & 15.45 \\
S16 & 5.7 & 46.34
\end{tabular}

TABLE 4: Range analysis results of relative wear rates.

\begin{tabular}{lcccc}
\hline Factor $(j)$ & $A$ & $B$ & $C$ & $D$ \\
\hline $\bar{K}_{j 1}$ & 79.47 & 77.64 & 71.137 & 80.893 \\
$\bar{K}_{j 2}$ & 81.91 & 83.74 & 83.333 & 83.13 \\
$\bar{K}_{j 3}$ & 87.81 & 84.755 & 85.365 & 78.253 \\
$K_{j 4}$ & 77.64 & 80.693 & 84.553 & 84.553 \\
Range $\left(R_{j}\right)$ & 10.17 & 7.115 & 14.228 & 6.3 \\
Rank order of factors & \multicolumn{4}{c}{$C>A>B>D$} \\
Optimum levels & $A_{3}$ & $B_{3}$ & $C_{3}$ & $D_{4}$ \\
\hline
\end{tabular}

that the best texture parameters are diameter $700 \mu \mathrm{m}$, triangle shape, depth $300 \mu \mathrm{m}$, and surface density $6 \%$. The results of this group of experiments are close to the results of recent studies $[23,28,30,33,34]$, indicating that the results of this group of experiments are reasonable.

4.4. Wear Morphology. After processing the data in the orthogonal experiment group, we selected the untextured sample, the orthogonal experiment optimal group sample, and the parameter median group sample for ultra-depth observation. Figures 11-13 show the local topography of abrasion.

Focusing on the observation of the wear morphology of the wear area, we can obtain the following conclusions by analyzing and comparing the three samples. The wear condition of the wear area in the optimal group of the orthogonal test in Figure 11(a) and the parameter median group in Figure 11(b) is relatively uniform. The grooves in the optimal group of the orthogonal test in Figure 11(a) are evenly distributed, with good continuity, and the grooves are long and shallow, indicating that the friction is in a relatively slight two-body wear stage. The wear groove in Figure 11(b) has a discontinuous distribution, and the groove depth has a certain degree of unevenness. This shows that the wear of the parameter median group is still mainly slight two-body wear, but there is a certain amount of three-body wear caused by debris, which causes uneven changes and discontinuities in the depth of the groove. Comparing the above two sets of test analysis graphs, we can see that, under the condition of the texture, the wear is dominated by abrasive wear. Among them, two-body wear dominates, and there is less three-body wear [47-49].

The abrasion morphology of the untextured sample is shown in Figure 11(c). The wear area of the smooth sample is larger than that of the above two samples, the pits and grooves appearing in the wear are obviously increased, and the continuity of the wear zone becomes worse, indicating that there is abrasive wear and adhesive wear. Abrasive wear occurs because the contact surface cannot effectively store the oil to ensure the stability of the oil film. When the oil film is damaged because the oil cannot be replenished in time, the two contact surfaces of the friction pair will gradually come into hard contact. The material of the hard surface is pressed into the soft surface, and the groove is plowed out, which produces a certain amount of wear debris, which cannot be carried out of the contact area by the oil due to the poor lubrication state [50]. The debris is squeezed by both sides of the contact surface, resulting in three-body wear, which intensifies the occurrence of plow-cutting. At the same time, as the friction progresses further, the friction between the wear debris and the two contact surfaces causes the temperature to rise, and adhesive wear and abrasive wear occur simultaneously [51]. As a result, adhesion and shearing alternately occur during friction, and eventually grooves and pit-shaped wear appear at the same time.

\section{Verification Tests and Analysis}

5.1. Verification of the Optimal Orthogonal Group. In order to verify the accuracy of the orthogonal experiment analysis, repeated experiments were performed on the optimal group of orthogonal analysis. According to the analysis results of the orthogonal experiment in Table 4, the parameters of the texture orthogonal optimal group are set to $700 \mu \mathrm{m}$ diameter, triangle, $300 \mu \mathrm{m}$ depth, and $8 \%$ areal density. The test conditions of this group of tests are the same as the previous test conditions. After the sample is tested, the abrasion mass measurement is performed again. The results are shown in Table 5.

5.2. Verification of the Dry Friction Control Group. In order to verify the conditions that affect texture, this section carried out an oil-free dry friction test on the optimal group of orthogonal analysis and the smooth copper samples without texture treatment. The two specimens of the dry friction test group were subjected to abrasion mass weighing and ultra-depth field photographs. The quality loss results are shown in Table 6.

Observe the two sets of dry friction samples with an ultra-depth of field in Figures 12 and 13. The friction coefficient comparison diagram is shown in Figure 14.

It can be found by comparing the two sets of dry friction test data that the mass loss of the orthogonal optimal group of specimens is greater than that of the smooth specimens. This shows that, in the case of oil-free friction, the sample 


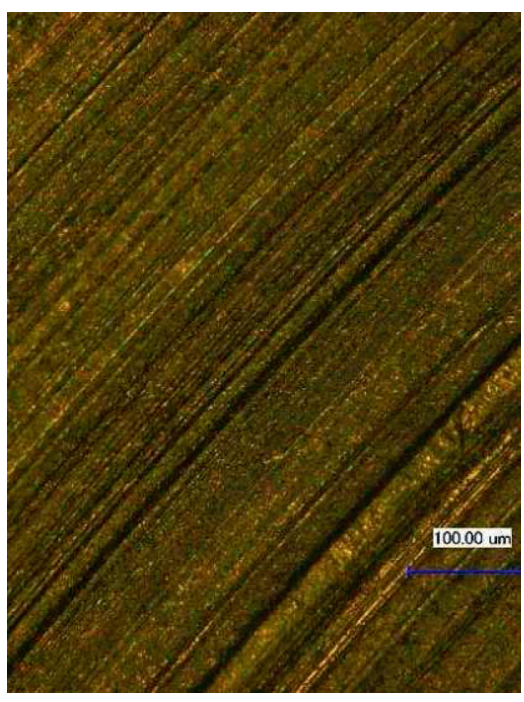

(a)

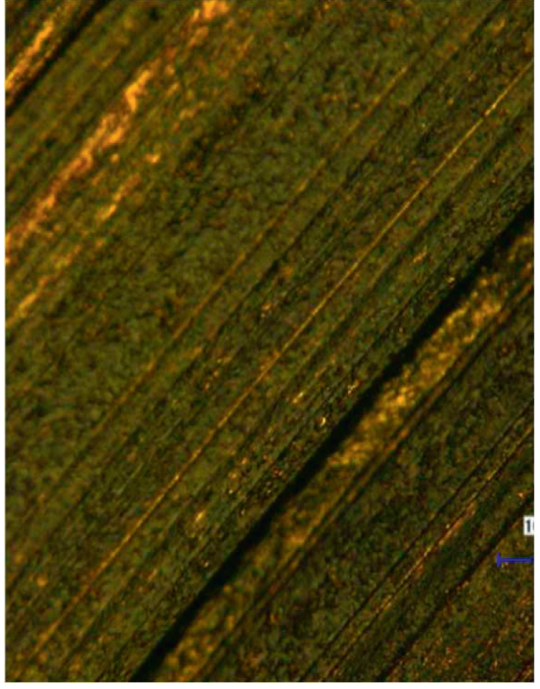

(b)

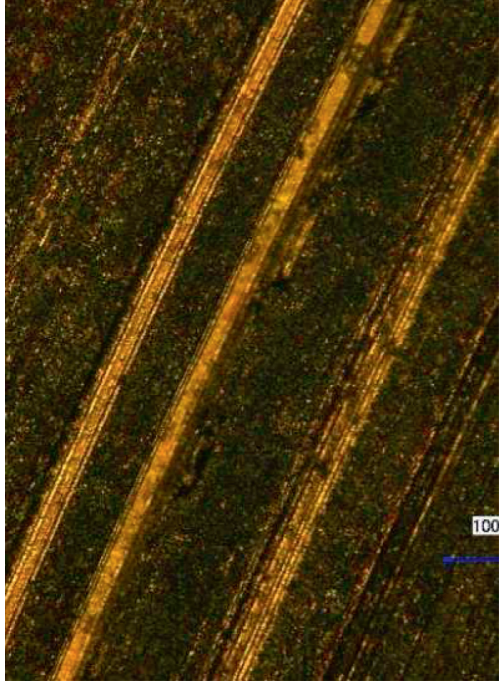

(c)

FIGURE 11: (a) Wear morphology of the orthogonal optimal test group. (b) Wear morphology of the parameter median group. (c) Wear morphology of the untextured sample.

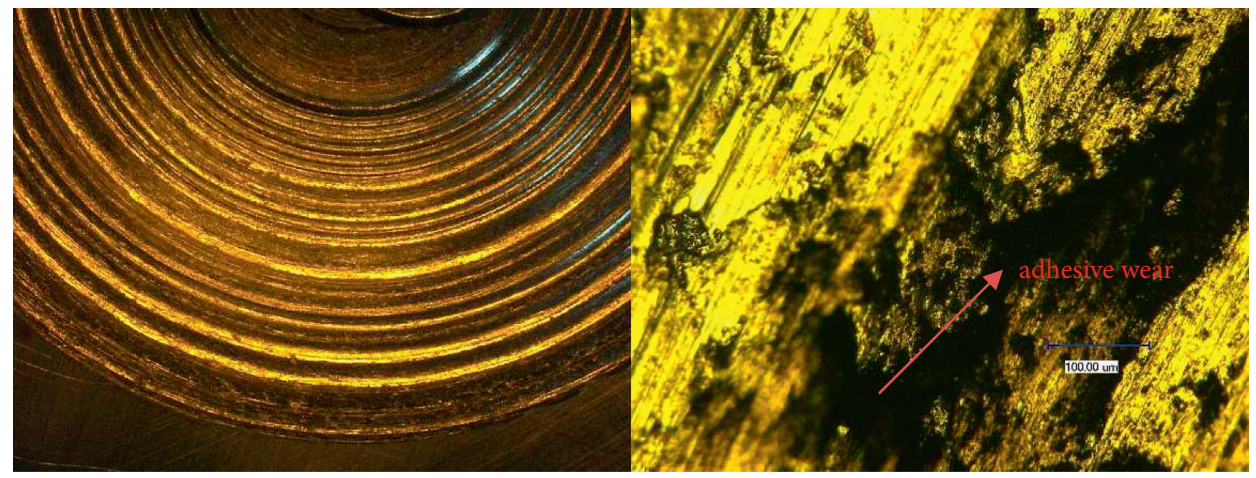

FIGURE 12: Dry grinding morphology of the smooth sample.

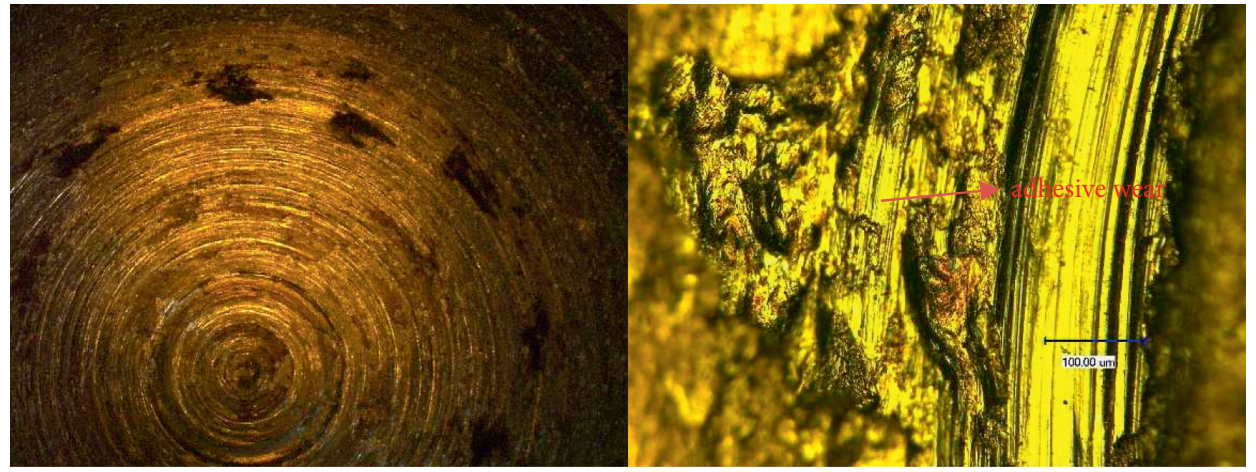

FIGURE 13: Dry grinding morphology diagram of the optimal orthogonal sample group.

with texture wears worse, that is, when there is no oil friction, the existence of texture plays a negative role. This is because the existence of texture is equivalent to increasing the roughness of the contact surface, resulting in increased wear. In the wear morphology in Figures 12 and 13, it can be found that a large amount of adhesive wear and abrasive wear occurred in the two test groups, which led to the flaky peeling of the material. When the friction surface gradually comes into direct contact, the surface of the $45 \#$ steel material with higher hardness is pressed into the surface of the 
TABLE 5: Mass wear rate under mixed lubrication conditions.

\begin{tabular}{lcc}
\hline Exp. no. & Wear loss $(\mathrm{mg})$ & Relative wear rate (\%) \\
\hline Smooth specimen & 12.3 & 100 \\
Orthogonal analysis optimal group & 0.1 & 0.81 \\
\hline
\end{tabular}

TABle 6: Mass wear rate under dry friction conditions.

\begin{tabular}{lcc}
\hline Exp. no. & Wear loss $(\mathrm{mg})$ & Relative wear rate (\%) \\
\hline Smooth specimen & 155.5 & 100 \\
Orthogonal analysis optimal group & 192.3 & 123.6 \\
\hline
\end{tabular}

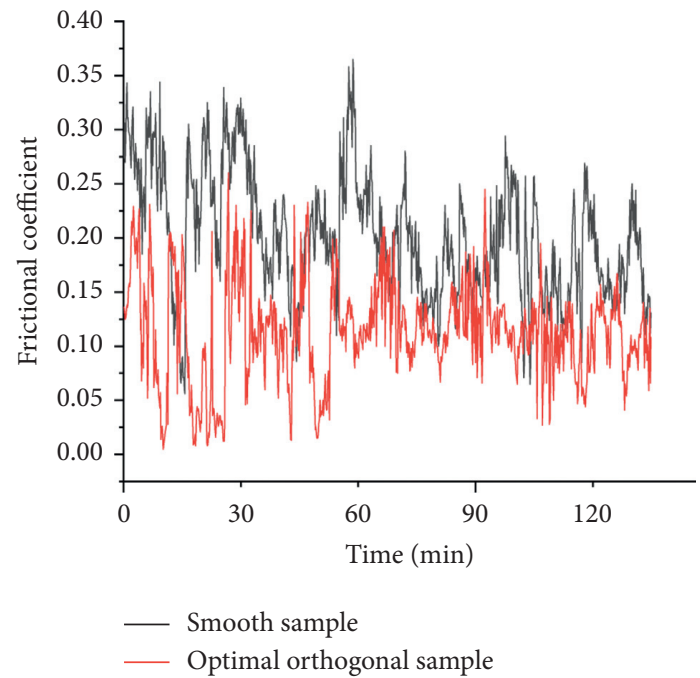

Figure 14: Comparison diagram of the friction coefficient in the dry friction test.

softer copper material, and during the sliding process the copper surface metal is continuously squeezed and grooves are plowed on the surface. A certain amount of metal debris is produced. This debris will be difficult to bring out of the friction interface by the oil due to the deterioration of the lubrication state and form three-body wear with the surfaces of the two materials, which will aggravate the occurrence of plowing, which will lead to an increase in the coefficient of friction. At the same time, as the friction progresses, the friction surface comes into direct contact, causing the two metals to produce instantaneous high temperature at the contact position, and the adhesion phenomenon occurs. Then, the adhesion part is sheared due to the action of shear stress. Under constant sliding friction, the adhesion and shearing occur alternately, and when they accumulate to a certain extent, they lead to adhesive wear [32, 35, 52, 53]. This shows that severe shear damage occurred during the wear process. In addition, the material in the orthogonal test group peeled more seriously, the peeling area was larger, and the delamination phenomenon was more obvious. According to the analysis of the wear morphology, the samples of the orthogonal optimal group wear more severely under dry friction conditions. This can also be verified by comparison with the friction coefficient graph of Figure 14 as the friction coefficient of the samples of the orthogonal optimal group is larger and the fluctuation is more obvious.

This section verifies the mass loss of the orthogonal optimal group under mixed friction conditions and compares the wear conditions of the orthogonal optimal group and smooth specimens under dry friction conditions. It shows that the texture works by maintaining the stability and bearing capacity of the oil film, thereby protecting the contact surface and reducing friction. Under dry friction conditions, the texture has a negative effect because it increases the roughness of the contact surface.

\section{Conclusion}

The influence of different texture parameters on the piston ring-sleeve friction pair sample was studied, and the parameters were optimized by the orthogonal design method and range analysis. The wear area and morphology were observed by taking pictures with an ultra-depth-of-field microscope, and the wear mechanism was analyzed. The influence of texture on the antifriction effect is analyzed by the mass-loss rate. The main conclusions obtained through these analyses are as follows:

(1) In this paper, a simulation analysis of the actual working conditions of the piston ring-sleeve friction pair of the hydraulic cylinder is carried out. Through simulation analysis and research, the size, shape, depth, and surface density of the texture have a certain influence on the thickness of the oil film and the ability of the oil to enter the texture. The simulation results show that the influence of the above four parameters should be considered when the actual sample is textured, which can play a theoretical guiding role in the actual industrial processing.

(2) The texturing treatment has a positive effect on reducing the friction and wear of the contact surface of the friction pair. Under mixed friction conditions, the mass wear rate of the sample after the texturing treatment has been significantly reduced, and the decrease in the friction coefficient also intuitively reflects this law. Through orthogonal experiment analysis and range analysis, the most influential parameters are texture depth, followed by texture size, shape, and surface density. The optimal values of these parameters are $300 \mu \mathrm{m}$ depth, $700 \mu \mathrm{m}$ diameter, triangle, and $8 \%$ areal density. As the size, 
depth, and surface density of the texture increase, the antifriction effect of the texture treatment becomes more obvious. The mechanism that affects this rule is the maintenance and replenishment of the texture to the oil film, which ensures that the contact surface is always in the friction condition with oil friction to the greatest extent and reduces the degree of friction and wear. The test results show that, in heavy-duty large hydraulic components, submillimeter-level textures play an important role in maintaining oil film and reducing friction and wear. Submillimeterlevel textures have broad industrial application prospects in large hydraulic components.

(3) A confirmatory experiment was carried out on the orthogonal optimal group. Tests have shown that the textured surface will have a positive effect only under mixed friction conditions, and the mechanism is that the texture maintains the stability of the oil film. The presence of texture under dry friction conditions is equivalent to increasing the roughness of the contact surface, which plays a negative role in friction. The test results show that, in large hydraulic components, due to the self-lubricating properties of the hydraulic system, the working conditions of the texture in the component friction pair are in a state of mixed friction, and its effect can be fully manifested.

(4) Under mixed friction conditions, the friction and wear of the piston ring-sleeve friction pair are dominated by two-body wear of abrasive wear, accompanied by a small amount of three-body wear, and the wear is relatively light and uniform. Under dry friction conditions, the wear is mainly adhesive wear, which is manifested in a large amount of pit-like wear and flaky peeling of materials. That is, under working conditions, the texture should be made to maintain the stability of the oil film to the greatest extent, to control the wear of the contact surface in a relatively stable state of abrasive wear. Under actual working conditions, hydraulic components are selflubricating; that is, the interior of the components is in a state of oil-rich friction or mixed friction for a long time. At this time, the texture, due to its mechanism of action, makes the oil film better preserved and finally makes the friction form of the piston ring-sleeve friction pair of the hydraulic cylinder in a mixed friction state, and the wear form is of a weak two-body wear type, which is effective. The morphology of the contact surface of the friction pair is guaranteed, and the service life is prolonged.

\section{Data Availability}

The data presented in this study are available from the corresponding author upon request.

\section{Conflicts of Interest}

The authors declare that there are no conflicts of interest regarding the publication of this article.

\section{Acknowledgments}

This work was supported by the National Natural Science Foundation of China (grant no. 51975396), Fund Program for the Scientific Activities of Selected Returned Overseas Professionals in Shanxi Province (No. 20200023), and research project supported by the Shanxi Scholarship Council of China (2021-138).

\section{References}

[1] Z. Li, Hydraulic Components and Systems, Mechanical Industry Press, Beijing, China, 2011, in Chinese.

[2] X.-l. Chen, L.-c. Zeng, X.-b. Chen, and Z.-p. Wu, "Friction performance of gap seal hydraulic cylinder based on optimization of elliptical texture," Chinese Hydraulics \& Pneumatics, vol. 3, no. 6, pp. 14-19, 2018, in Chinese.

[3] B. Bhushan, "Biomimetics: lessons from nature-an overview," Philosophical Transactions of the Royal Society A: Mathematical, Physical and Engineering Sciences, vol. 367, no. 1893, pp. 1445-1486, 2009.

[4] B. Dean and B. Bhushan, "Shark-skin surfaces for fluid-drag reduction in turbulent flow: a review," Philosophical Transactions of the Royal Society A: Mathematical, Physical and Engineering Sciences, vol. 368, no. 1929, pp. 4775-4806, 2010.

[5] W. Jearl, "More on boomerangs, including their connection with the dimpled golf ball," Scientific American, vol. 31, p. 180, 1979.

[6] D. Gropper, L. Wang, and T. J. Harvey, "Hydrodynamic lubrication of textured surfaces: a review of modeling techniques and key findings," Tribology International, vol. 94, pp. 509-529, 2016.

[7] D. B. Hamilton, J. A. Walowit, and C. M. Allen, "A theory of lubrication by microirregularities," Journal of Basic Engineering, vol. 88, no. 1, pp. 177-185, 1966.

[8] M. Wakuda, Y. Yamauchi, S. Kanzaki, and Y. Yasuda, "Effect of surface texturing on friction reduction between ceramic and steel materials under lubricated sliding contact," Wear, vol. 254, no. 3-4, pp. 356-363, 2003.

[9] M. Varenberg, G. Halperin, and I. Etsion, "Different aspects of the role of wear debris in fretting wear," Wear, vol. 252, no. 1112, pp. 902-910, 2002.

[10] H. Yamakiri, S. Sasaki, T. Kurita, and N. Kasashima, "Effects of laser surface texturing on friction behavior of silicon nitride under lubrication with water," Tribology International, vol. 44, no. 5, pp. 579-584, 2011.

[11] S. Bhowmick and A. T. Alpas, "Minimum quantity lubrication drilling of aluminium-silicon alloys in water using diamondlike carbon coated drills," International Journal of Machine Tools and Manufacture, vol. 48, no. 12-13, pp. 1429-1443, 2008.

[12] P. Andersson, J. Tamminen, and C.-E. Sandström, Piston Ring Tribology: A Literature Survey, VTT Technical Research Centre of Finland, Espoo, Finland, 2002.

[13] A. B. Zavos and P. G. Nikolakopoulos, "Simulation of piston ring tribology with surface texturing for internal combustion engines," Lubrication Science, vol. 27, no. 3, pp. 151-176, 2015.

[14] L. Wei, B. Q. Gu, X. Feng, and J. J. Sun, "Research on friction characteristic of end faces of mechanical seals," Advanced Tribology, Springer, Berlin, Germany, pp. 304-308, 2009.

[15] N. Tala-Ighil, P. Maspeyrot, M. Fillon, and A. Bounif, "Effects of surface texture on journal-bearing characteristics under steady-state operating conditions," Proceedings of the 
Institution of Mechanical Engineers, Part J: Journal of Engineering Tribology, vol. 221, no. 6, pp. 623-633, 2007.

[16] N. Tala-Ighil, M. Fillon, and P. Maspeyrot, "Effect of textured area on the performances of a hydrodynamic journal bearing," Tribology International, vol. 44, no. 3, pp. 211-219, 2011.

[17] J. Pan, K. Feng, L. He, K. Zhuang, J. Ni, and J. Lv, "Influence of different textures on machining performance of a milling tool," Advances in Materials Science and Engineering, vol. 2020, Article ID 1724241, 11 pages, 2020.

[18] Y. Qiu and M. M. Khonsari, "Experimental investigation of tribological performance of laser textured stainless steel rings," Tribology International, vol. 44, no. 5, pp. 635-644, 2011.

[19] I. Etsion, Y. Kligerman, and G. Halperin, "Analytical and experimental investigation of laser-textured mechanical seal faces," Tribology Transactions, vol. 42, no. 3, pp. 511-516, 1999.

[20] X. Wang, K. Kato, K. Adachi, and K. Aizawa, "Loads carrying capacity map for the surface texture design of $\mathrm{SiC}$ thrust bearing sliding in water," Tribology International, vol. 36, no. 3, pp. 189-197, 2003.

[21] H. Deng, S. He, F. Mao, and C. Wang, "Effects of micropit depths on tribology performance of textured," Advances in Materials Science and Engineering, vol. 2018, Article ID 9501708, 7 pages, 2018.

[22] A. Guzek, P. Podsiadlo, and G. W. Stachowiak, "Optimization of textured surface in 2D parallel bearings governed by the Reynolds equation including cavitation and temperature," Tribology Online, vol. 8, no. 1, pp. 7-21, 2013.

[23] D. G. Coblas, A. Fatu, A. Maoui, and M. Hajjam, "Manufacturing textured surfaces: state of art and recent developments," Proceedings of the Institution of Mechanical Engineers, Part J: Journal of Engineering Tribology, vol. 229, no. 1, pp. 3-29, 2015.

[24] H. Costa and I. Hutchings, "Some innovative surface texturing techniques for tribological purposes," Proceedings of the Institution of Mechanical Engineers, Part J: Journal of Engineering Tribology, vol. 229, no. 4, pp. 429448, 2015.

[25] I. Etsion, "Modeling of surface texturing in hydrodynamic lubrication," Friction, vol. 1, no. 3, pp. 195-209, 2013.

[26] M. Xiao, Y. Zhang, H. Wang, and L. Zhang, "Direction of groove detection for wear image of four-ball friction test based on Gray difference of inclination angle," Advances in Materials Science and Engineering, vol. 2020, Article ID 9579853, 7 pages, 2020.

[27] T. Nanbu, N. Ren, Y. Yasuda, D. Zhu, and Q. J. Wang, "Microtextures in concentrated conformal-contact lubrication: effects of texture bottom shape and surface relative motion," Tribology Letters, vol. 29, no. 3, pp. 241-252, 2008.

[28] H. Zhang, D. Y. Zhang, M. Hua, G. N. Dong, and K. S. Chin, "A study on the tribological behavior of surface texturing on Babbitt alloy under mixed or starved lubrication," Tribology Letters, vol. 56, no. 2, pp. 305-315, 2014.

[29] X. Wang, J. Wang, B. Zhang, and W. Huang, "Design principles for the area density of dimple patterns," Proceedings of the Institution of Mechanical Engineers, Part J: Journal of Engineering Tribology, vol. 229, no. 4, pp. 538-546, 2015.

[30] Y. Henry, J. Bouyer, and M. Fillon, “An experimental analysis of the hydrodynamic contribution of textured thrust bearings during steady-state operation: a comparison with the untextured parallel surface configuration," Proceedings of the Institution of Mechanical Engineers, Part J: Journal of Engineering Tribology, vol. 229, no. 4, pp. 362-375, 2014.
[31] A. Gherca, A. Fatu, M. Hajjam, and P. Maspeyrot, "Effects of surface texturing in steady-state and transient flow conditions: two-dimensional numerical simulation using a massconserving cavitation model," Proceedings of the Institution of Mechanical Engineers, Part J: Journal of Engineering Tribology, vol. 229, no. 4, pp. 505-522, 2014.

[32] Y. Xu, Q. Zheng, J. Geng et al., "Synergistic effects of electroless piston ring coatings and nano-additives in oil on the friction and wear of a piston ring/cylinder liner pair," Wear, vol. 422-423, pp. 201-211, 2019.

[33] Y. Xu, Y. Peng, K. D. Dearn, T. You, J. Geng, and X. Hu, "Fabrication and tribological characterization of laser textured boron cast iron surfaces," Surface and Coatings Technology, vol. 313, pp. 391-401, 2017.

[34] Y. Xu, J. Yu, J. Geng et al., "Characterization of the tribological behavior of the textured steel surfaces fabricated by photolithographic etching," Tribology Letters, vol. 66, no. 2, p. 55, 2018.

[35] Y. Peng, Y. Xu, J. Geng, K. D. Dearn, and X. Hu, “Tribological assessment of coated piston ring-cylinder liner contacts under bio-oil lubricated conditions," Tribology International, vol. 107, pp. 283-293, 2017.

[36] Y. Xu, Q. Zheng, R. Abuflaha et al., "Influence of dimple shape on tribofilm formation and tribological properties of textured surfaces under full and starved lubrication," Tribology International, vol. 136, pp. 267-275, 2019.

[37] F. Sahlin, S. B. Glavatskih, T. r. Almqvist, and R. Larsson, "Two-dimensional CFD-analysis of micro-patterned surfaces in hydrodynamic lubrication," Journal of Tribology, vol. 127, no. 1, pp. 96-102, 2005.

[38] S. Cupillard, S. Glavatskih, and M. J. Cervantes, "3D thermohydrodynamic analysis of a textured slider," Tribology International, vol. 42, no. 10, pp. 1487-1495, 2009.

[39] S. Cupillard, M. J. Cervantes, and S. Glavatskih, "Pressure buildup mechanism in a textured inlet of a hydrodynamic contact," Journal of Tribology, vol. 130, Article ID 021701, 2008.

[40] S. Cupillard, S. Glavatskih, and M. J. Cervantes, "Inertia effects in textured hydrodynamic contacts," Proceedings of the Institution of Mechanical Engineers, Part J: Journal of Engineering Tribology, vol. 224, 2010.

[41] S. Du and Y. Li, "Effect of annealing on microstructure and mechanical properties of magnetron sputtered $\mathrm{Cu}$ thin films," Advances in Materials Science and Engineering, vol. 2015, Article ID 969580, 8 pages, 2015.

[42] D. G. Fouflias, A. G. Charitopoulos, C. I. Papadopoulos, L. Kaiktsis, and M. Fillon, "Performance comparison between textured, pocket, and tapered-land sector-pad thrust bearings using computational fluid dynamics thermohydrodynamic analysis," Proceedings of the Institution of Mechanical Engineers, Part J: Journal of Engineering Tribology, vol. 229, no. 4, pp. 376-397, 2014.

[43] C. I. Papadopoulos, L. Kaiktsis, and M. Fillon, "Computational fluid dynamics thermohydrodynamic analysis of threedimensional sector-pad thrust bearings with rectangular dimples," Journal of Tribology, vol. 136, Article ID 011702, 2014.

[44] Z. Hu, B. Nagarajan, X. Song, R. Huang, W. Zhai, and J. Wei, "Formation of SS316L single tracks in micro selective laser melting: surface, geometry, and defects," Advances in Materials Science and Engineering, vol. 2019, Article ID 9451406, 9 pages, 2019.

[45] X. Yang, Y. Fu, J. Ji, T. Chen, and C. Pan, "Study on tribological properties of surface concave convex micro-texture on 
the mold steel," Industrial Lubrication and Tribology, vol. 72, no. 10, pp. 1167-1171, 2020.

[46] K. Tønder, "Hydrodynamic effects of tailored inlet roughnesses: extended theory," Tribology International, vol. 37, pp. 137-142, 2004.

[47] H. Zhang, X. Yan, Q. Hou, and Z. Chen, "Effect of cyclic cryogenic treatment on wear resistance, impact, toughness, and microstructure of $42 \mathrm{CrMo}$ steel and its optimization," Advances in Materials Science and Engineering, vol. 2021, Article ID 8870282, 13 pages, 2021.

[48] Y. Wan and D.-S. Xiong, "The effect of laser surface texturing on frictional performance of face seal," Journal of Materials Processing Technology, vol. 197, no. 1-3, pp. 96-100, 2008.

[49] A. Kovalchenko, O. Ajayi, A. Erdemir, G. Fenske, and I. Etsion, "The effect of laser surface texturing on transitions in lubrication regimes during unidirectional sliding contact," Tribology International, vol. 38, no. 3, pp. 219-225, 2005.

[50] W. M. D. Silva, M. P. Suarez, A. R. Machado et al., "Effect of laser surface modification on the micro-abrasive wear resistance of coated cemented carbide tools," Wear, vol. 302, no. 12, pp. 1230-1240, 2013.

[51] T. Ibatan, M. S. Uddin, and M. A. K. Chowdhury, "Recent development on surface texturing in enhancing tribological performance of bearing sliders," Surface and Coatings Technology, vol. 272, no. 272, pp. 102-120, 2015.

[52] S. Wen, Principle of Tribology, Tsinghua University Press, Beijing, China, 2018, in Chinese.

[53] Y. Zhang, Dry Tribology of Materials, Science Press, Beijing, China, 2007, in Chinese. 